\title{
Minimum gas injection of gas drilling while temperature and pressure coupling
}

\author{
Pengfei $\mathrm{Ju}^{1}$, Zhiyi Yang ${ }^{1}$, Weixuan $\mathrm{Li}^{1}$, Yong $\mathrm{Guo}^{1}$ and Zhongxi Zhu ${ }^{2, *}$ \\ ${ }^{1}$ Engineering Technology Institute of PetroChina Xin Jiang Oil Field Company, 834000, Karamay, Xinjiang, China \\ ${ }^{2}$ Petroleum Engineering College, Yangtze University, 430100, Wuhan, Hubei, China
}

\begin{abstract}
Gas drilling technology not only has the advantages of avoiding well leakage, shale hydration expansion, reservoir pollution and other issues, but also can greatly improve the drilling speed 4 to 8 times, it is helpful to timely discover and effectively protect reservoir and improve recovery efficiency and single well production of oil and gas reservoir, especially has important significance for hard strata and dense reservoir exploration. However, there are some problems hindered the promotion of this technology, such as gas is hard to carries cuttings and gas hole blocking. One of the key technologies to solve these problems is the determination of gas volume. Most of today's literature use formation temperature instead of annulus temperature to calculate minimum gas volume. Owing to gas' PVT effect, temperature is dramatically influenced by pressure flow velocity, there will be big error if we use formation temperature instead of annulus temperature. Meanwhile, most of traditional minimum gas volume methods use top of the drill collar as key point. In this study, we found that on the top of the drill collar, the carrying kinetic energy of gas is not is not necessarily the minimum, and change of the key position is strongly influenced by wellbore structure and make-up of drill tool. Minimum gas volume determined by applying temperature - pressure coupling calculation is more close to site construction, under the given conditions, error of the minimum gas volume is about $0.4 \%$.
\end{abstract}

\section{Introduction}

In the design of gas drilling engineering, it is necessary to calculate the minimum gas flow and surface injection pressure in order to select the appropriate ground equipment (air compressor, booster, etc.) and predict the bottom hole pressure accurately. At present, the Angel [1-4] model is used to calculate the minimum volume flow rate of gas drilling. But drilling practice shows that the calculation results of the model are often lower than the minimum volume flow rate of $25 \%$. The reasons are as follows: Due to the compressibility of gas, the pressure and temperature of the gas flow influence each other. The distribution of temperature and pressure in the flow channel has great influence on the gas flow state and the flow parameters. So the calculation of gas injection volume should be based on the temperature and pressure during the drilling process. The key point of traditional minimum gas injection rate calculation method is drill collar's top. However, the research found that the minimum of wellbore gas carrying rock kinetic energy is not necessarily at the top of the drill collar, the change of the key point is influenced by the well structure and drilling tool combination. Gas injection volume, temperature, pressure, well structure, and the geometrical dimension of well bore influence each other, so the "key point" position is very important to calculate the minimum gas injection volume.
At present, gas drilling wellbore flow model often use formation temperature as annulus temperature. Without considering the effect of heat transfer of the wellbore fluid and the formation, which will lead to error, and with well depth increasing, the error will increase. So on the basis of previous studies, using pressure temperature coupling calculation model, consider the drill pipe fluid and annulus fluid heat exchange, annulus fluid and formation near the wellbore exchange and the temperature change of the gas flowing through the bit nozzle process, establish the borehole internal fluid pressure temperature coupling calculation model and solve it. According to the different structure of the well and the geometric size of the hole, the corresponding minimum gas injection "key point" are obtained. The minimum gas injection volume is calculated according to the modified model [5-6] of the minimum kinetic energy method.

\section{Differential equation model and solution}

\subsection{Differential equation}

* Corresponding author: zhuzhongxi@126.com 


\subsubsection{Mass conservation equation}

$$
\rho \frac{d v}{d z}+v \frac{d \rho}{d z}=0
$$

\subsubsection{Momentum conservation equation}

$$
-\frac{1}{\rho} \frac{d p}{d z}-f \frac{v|v|}{2 d}+g=\frac{v d v}{d z}
$$

\subsubsection{Energy conservation equation}

$$
q+w \frac{d}{d z}\left|h+\frac{1}{2} v^{2}-g z\right|=0
$$

\subsubsection{Equation for calculating heat loss of} drilling fluid in unit length and unit time

$$
q=2 a\left(T_{e}-T\right) w
$$

where, $\quad a=\frac{\pi r_{p i} U_{t i} k_{e}}{w\left[r_{p i} U_{t i} f\left(t_{D}\right)+k_{e}\right]}, f$ is

frictional coefficient, $w$ is mass flow, $\mathrm{kg} / \mathrm{s}$,

$f\left(t_{D}\right)$ is dimensionless time function, $U_{t i}$ is total wellbore heat transfer coefficient; $k_{e}$ is formation thermal conductivity, $\mathrm{J} / \mathrm{m} \cdot \mathrm{k}$; Pressure gradient equation:

$\left(\frac{d P}{d z}\right)_{t}=\left(\frac{d P}{d z}\right)_{h}+\left(\frac{d P}{d z}\right)_{f}+\left(\frac{d P}{d z}\right)_{a}$

Where, $\left(\frac{d P}{d z}\right)_{t}$ is total pressure gradient,

$\left(\frac{d P}{d z}\right)_{h}$ is hydraulic pressure gradient,

$\left(\frac{d P}{d z}\right)_{f}$ is frictional pressure gradient,

$\left(\frac{d P}{d z}\right)_{a}$ is accelerated pressure gradient, $P a / m$.

Temperature gradient equation:

$$
\left(\frac{d T}{d z}\right)_{t}=\left(\frac{d T}{d z}\right)_{v}+\left(\frac{d T}{d z}\right)_{h}
$$

Where, $\left(\frac{d T}{d z}\right)_{t}$ is total temperature gradient,

$\left(\frac{d T}{d z}\right)_{v}$ is temperature gradient of energy

transfer in the vertical direction, $\left(\frac{d T}{d z}\right)_{h}$ is temperature gradient of energy transfer in the horizontal direction。

The annulus pressure and temperature gradient equation are similar to the equation (1) (6), it's not described in this article.

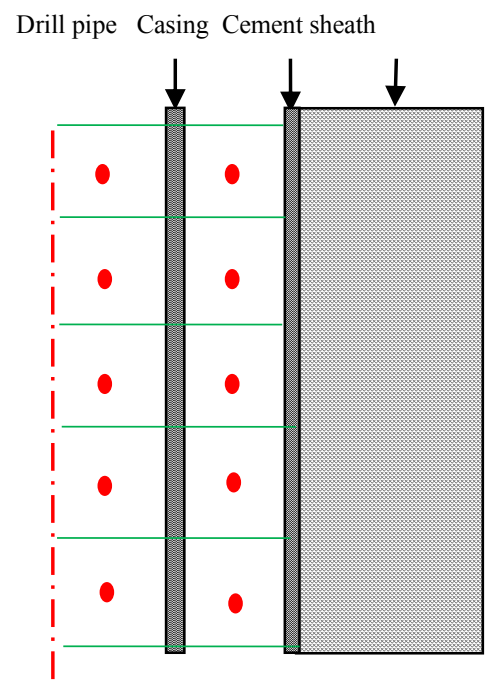

Fig.1 Physical model of wellbore flow

\subsection{Solution of differential equation}

The exit of the annulus is taken as the starting point, set the initial value of drill pipe and annulus temperature as the formation temperature, iterate the pressure against the flow direction, until the drill column inlet pressure calculated.

The above two steps are an iteration loop, and then use this method to calculate the temperature and pressure, and if the temperature error of each unit is less than the error allowable value, the iteration is successful.

\section{Case analysis}

Based on the case data in the literature [2], the well depth is $3650 \mathrm{~m}$, Casing shoe depth $2840 \mathrm{~m}$, drill pipe internal diameter $108.6 \mathrm{~mm}$, external diameter $127.0 \mathrm{~mm}$, drill collar $244 \mathrm{~m}$, internal diameter $71.4 \mathrm{~mm}$, external diameter $159.0 \mathrm{~mm}$, drill bit diameter $215.9 \mathrm{~mm}$, drilling speed $10 \mathrm{~m} / \mathrm{h}$, surface temperature $9^{\circ} \mathrm{C}$, injection temperature $38^{\circ} \mathrm{C}$, geothermal gradient $4.07^{\circ} \mathrm{C} / \mathrm{hm}$, air density $1.225 \mathrm{~kg} / \mathrm{m}^{3}$, cuttings density $2.7 \mathrm{~g} / \mathrm{cm}^{3}, 3 \mathrm{bit}$ nozzles, diameter $12 \mathrm{~mm}$, cutting diameter of drill bit 5 $\mathrm{mm}$, discharge cuttings diameter $1 \mathrm{~mm}$, broken work index $3.0 \mathrm{~kW} \cdot \mathrm{h} / \mathrm{t}$ 。 When the gas injection volume is 98 $\mathrm{m}^{3} / \mathrm{min}$, the calculation results are shown in Fig. 2 and Fig.3: 


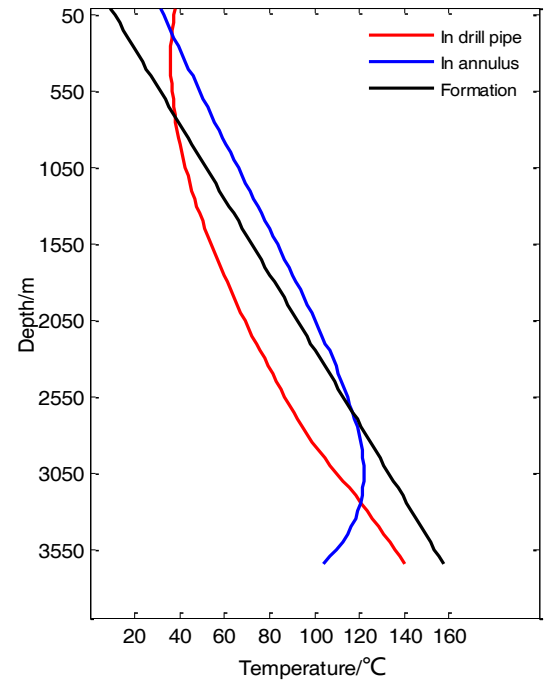

Fig 2 Downhole temperature distribution in case 1

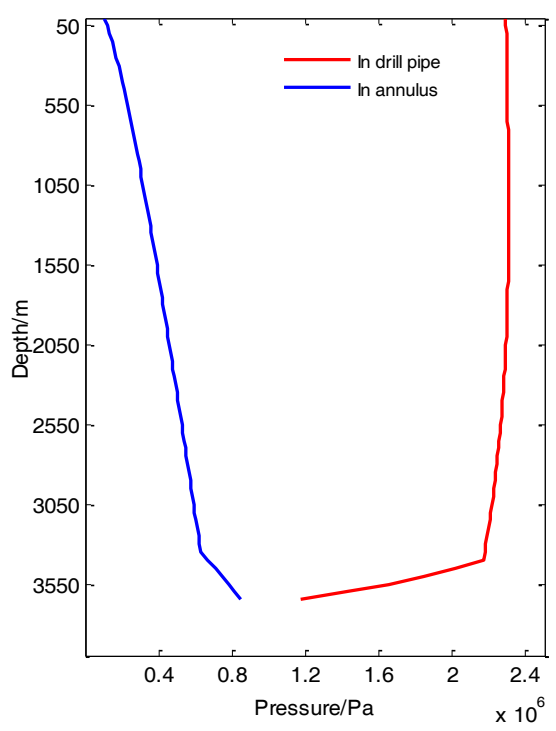

Fig 3 Downhole pressure distribution in case 1

Figure 2 and figure 3 shows the pressure and temperature distribution in the wellbore. Near the bottom of the rock temperature is $157.5{ }^{\circ} \mathrm{C}$, while the annulus temperature is only $103.7{ }^{\circ} \mathrm{C}$, the gap between the $53.8^{\circ} \mathrm{C}$, which shows that there is a big gap between the annulus temperature and formation temperature.

If change the assembly and the well depth, as shown in table 1:

Table 1 Different rig assembly and well depth working conditions

\begin{tabular}{cccc}
\hline Case & $\begin{array}{c}\text { Drill } \\
\text { diameter } \\
(\mathrm{mm})\end{array}$ & $\begin{array}{c}\text { Collar out } \\
\text { diameter } \\
(\mathrm{mm})\end{array}$ & $\begin{array}{c}\text { Well depth } \\
(\mathrm{m})\end{array}$ \\
\hline Case 1 & 215.9 & 159.0 & 3650 \\
Case 2 & 241.3 & 171.45 & 3650 \\
Case 3 & 241.3 & 171.45 & 3250 \\
\hline
\end{tabular}

Case 2 calculation results are shown in Fig.4,5:

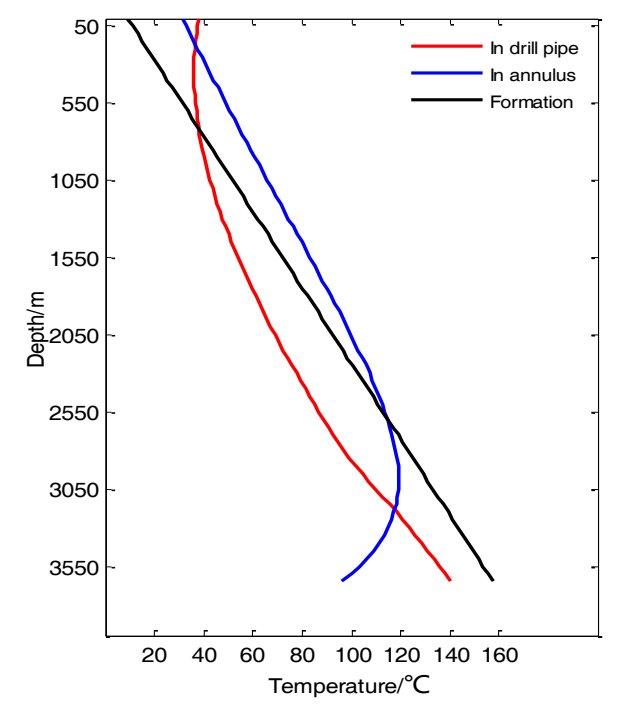

Fig 4 Downhole temperature distribution in case2

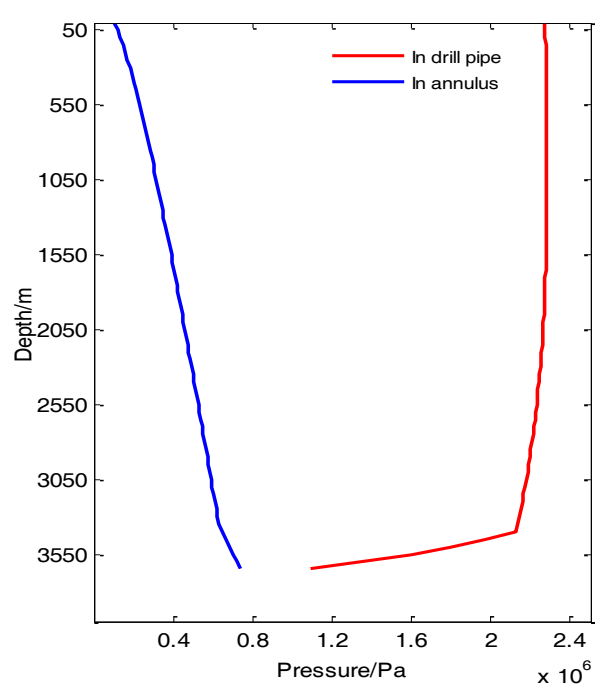

Fig 5 Downhole pressure distribution in case2

From the comparison of Fig. 2 and Fig 4, Fig 3 and Fig 5, only changing the drill bit and the drill collar size, distribution of temperature and pressure changes smaller, but in selection of the "key point" has varied greatly. Contrast Fig. 6 and Fig. 7, due to the change of hole size, gas kinetic energy minimum location (key point) from the upper casing shoe to the drill collar and drill pipe joints.

As can be seen from Fig. 8 when the bit from the upper casing distance is very short, the "key point" is no longer the drill collar top in case 2, but the upper casing shoe. It shows that the determination of the "key point" is also affected by the well depth. 


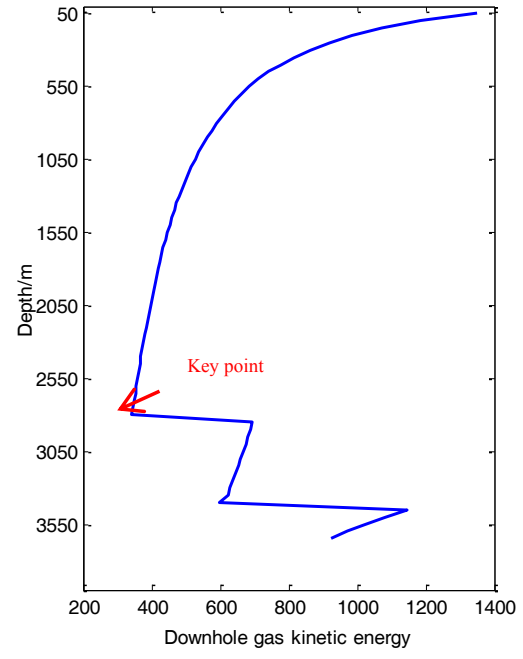

Fig 6 Downhole gas kinetic energy in case1

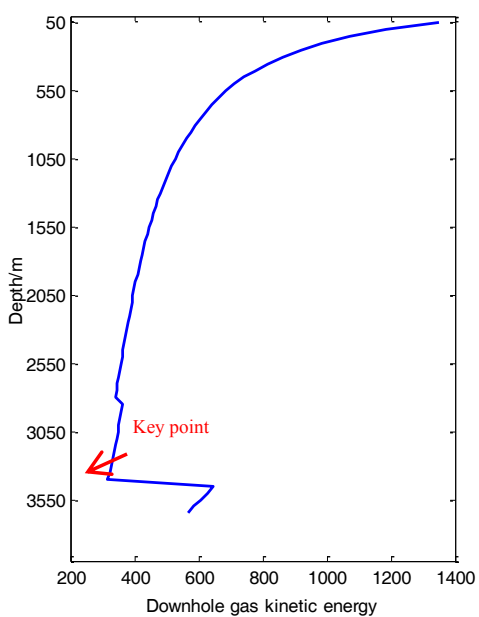

Fig 7 Downhole gas kinetic energy in case2

Case 3 calculation results are shown in Fig. 8:

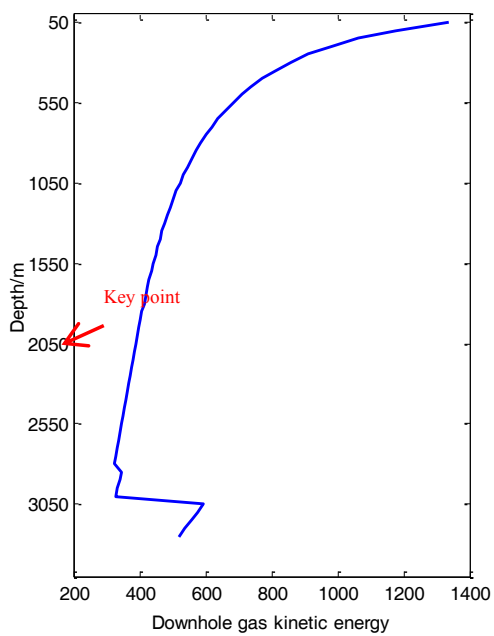

Fig 8 Downhole gas kinetic energy in case3

\section{Conclusion}

(1) Considering the heat exchange between gas and formation, the calculated annular gas temperature is greatly different from the formation temperature, which can tell that the old method of directly using formation temperature as well temperature can result in significant error, thus violate the accuracy of the calculation.

(2) Considering the fact that well structure and geometry dimension exert a large influence on the position of key point and comparing these 3 different working condition, a conclusion can be drew that the method of working out the minimum air input while using the top the drill collar as key point is not accurate enough.

(3) When taking the heat conduction of the well and the actual condition of the key point into account, a more accurate calculation can be figured out, closer to the minimum air input used by the working practice, with only $0.4 \%$ of error.

\section{References}

1. Guo Boyun, Chalambor A. Gas volume requirements for underbalanced drilling. Translated by Xu Siping. Beijing: Sinopec Press,2006:9-28.

2. MITCHELL R F. Simulation of air and mist drilling for geothermal wells. SPE 10234

3. KABIR C S, HASAN A R, KOUBA G E, AMEEN $\mathrm{M} M$.Determining circulating fluid temperature in drilling, workover, and well control Operations . SPE 24581

4. HASAN A R, KABIR C S, AMEEN M M, XIAOWEIWANG.A mechanistic model for circulating fluid temperature . SPE 27848.

5. Wan Jinquan. Design and calculation of hydrodynamic parameters in air drilling. Beijing: China University of Petroleum (East China), 2008

6. Liu Gonghui, Liu Wei. A new method for calculating the minimum volumetric flow rate of air in air-nitrogen drilling. Acta Petrolei Sinica ,2008, 29(4): 629-632 